\title{
Effect of Biofouling on Stability of Polycarbonate in Tropical Seawater
}

\author{
Trishul Artham ${ }^{1}$, M. Sudhakar ${ }^{1}$, Mukesh Doble ${ }^{*}, 1$, V.R. Umadevi ${ }^{2}$, R.R. Viduthalai ${ }^{2}$, \\ K. Suresh Kumar ${ }^{2}$, P. Sriyutha Murthy ${ }^{2}$ and R. Venkatesan ${ }^{2}$ \\ ${ }^{I}$ Department of Biotechnology, Indian Institute of Technology Madras, Chennai 600036, India \\ ${ }^{2}$ OSTI, National Institute of Ocean Technology, Chennai-601302, India
}

\begin{abstract}
The effect of biofouling on physical, chemical and mechanical changes of Bisphenol A polycarbonate immersed at a depth of three meters at two different locations (Port and FSI, Chennai, India) in the Bay of Bengal Sea over a period of six months was the subject of this study. Biofouling in terms of total suspended solids, organic matter and total viable count was higher at Port than at FSI, probably because of higher dissolved oxygen at the former than at the latter site. An increase in glass transition temperature (from $133^{\circ} \mathrm{C}$ to 147 and $144^{\circ} \mathrm{C}$ at Port and FSI respectively) was observed in the samples indicating loss of amorphous region and conformational change in the polymer. A two fold decrease in tensile strength, a 33\% decrease in contact angle and, a reduction in the tertiary methyl and carbonate carbonyl indices were observed. These findings indicate that polycarbonate undergoes a combination of biodeterioration and biodegradation under these conditions.
\end{abstract}

Keywords: Degradation, waste disposal, biodeterioration, Bay of Bengal, bisphenol A polycarbonate.

\section{INTRODUCTION}

There has been a great deal of interest in recent years in the synthesis and usage of polycarbonate [1] (especially bisphenol A polycarbonate), since it finds extensive applications ranging from windshields on boats to biomonitoring units in water analysis, but only few reports deal with its biodegradation $[2,3]$. When this polymer is exposed to seawater there is a possibility of Bisphenol A (BPA), one of the monomers, leaching out [4]. BPA has been classified as an endocrine disruptor due to its estrogenic action and has an acute toxicity in the range of $1-10 \mu \mathrm{g} \mathrm{ml}^{-1}$ for freshwater and marine species [5]. Therefore, its release into the aquatic environment is of significant concern. Hence it is important to assess the biodegradability and impact of polycarbonate disposed in the marine environment.

Any material immersed in aqueous environment or under high humidity conditions are equally susceptible to biofouling and in turn to biodegradation. This definition of biodegradation is distinguished from biodeterioration or deterioration, where a polymer film is gradually fragmented due to biological or environmental effects, such as water, radiation, or mechanical forces. Factors such as humidity, temperature, $\mathrm{pH}$, salinity, dissolved oxygen and the supply of different nutrients have important effects on the microbial degradation of polymers, and so these conditions must be considered when the biodegradability of these plastics is tested. The characteristics of the polymer such as structure, morphology, crystallinity, presence of functional groups, solubility and molecular weight also influence rates of biodegradation [2]. There are some reports on degradation of various polymers in sea water, which include polyurethane [6], starch blended low density polyethylene [7], polyesters [8] and polyolefins

*Address correspondence to this author at the Department of Biotechnology, Indian Institute of Technology Madras, Chennai 600036, India; Tel: +91 44 2257 4107; Fax: +91 442257 4102; E-mail: mukeshd@iitm.ac.in
[9]. Few authors have made comparison of biofouling on different artificial and natural substrata [10,11]. Polycarbonate was also a subject of study where it was used as a substrate for biofilm growth in lakes [12,13], in drinking water distribution system [14], in nanofiltration membranes in reverse osmosis process [15], and for biomonitoring pollutants by growing biofilms on this polymer [16], but these authors do not report the fate of the polycarbonate.

No reports have been published so far on biofouling and its effects on polycarbonate in sea water. The aim of this work is to estimate the fouling and its impact on degradation of Bisphenol A polycarbonate immersed at two different locations in the Bay of Bengal near Chennai, India.

\section{MATERIALS AND METHODS}

\subsection{Materials}

Commercial grade Bisphenol A polycarbonate (PC) $\left(\right.$ Lexan $\left.^{\circledR}\right)$ sheets of $1.5 \mathrm{~mm}$ thickness cut into $150 \times 100 \mathrm{~mm}$ coupons were used in the present study. The average weight $\pm \mathrm{SD}$ of the samples was $35.3 \pm 0.2 \mathrm{~g}$. This polymer was obtained from Industrial insulations ltd, Chennai 600001, India and used as supplied.

\subsection{Environment}

The polycarbonate samples were immersed in the ocean waters of Bay of Bengal (Fig. 1) at a depth of three meters near Chennai Port (Latitude $=13^{\circ} 6^{\prime} 26^{\prime \prime} \mathrm{N}$, Longitude $=80^{\circ}$ $18^{\prime} 14^{\prime \prime}$ E) and near Fisheries survey of India (FSI) (Latitude $=13^{\circ} 74^{\prime} 34^{\prime \prime} \mathrm{N}$, Longitude $=80^{\circ} 17^{\prime} 49^{\prime \prime} \mathrm{E}$ ). The samples were vertically submerged in the water in Fiber reinforced racks from March to August 2006. The racks were fixed to plastic buoys filled with polyurethane foam. 18 coupons (3 samples for each month) were used at each site. The characteristic parameters of the sea water such as temperature, $\mathrm{pH}$, dissolved oxygen (DO), salinity, oxidation and reduction 


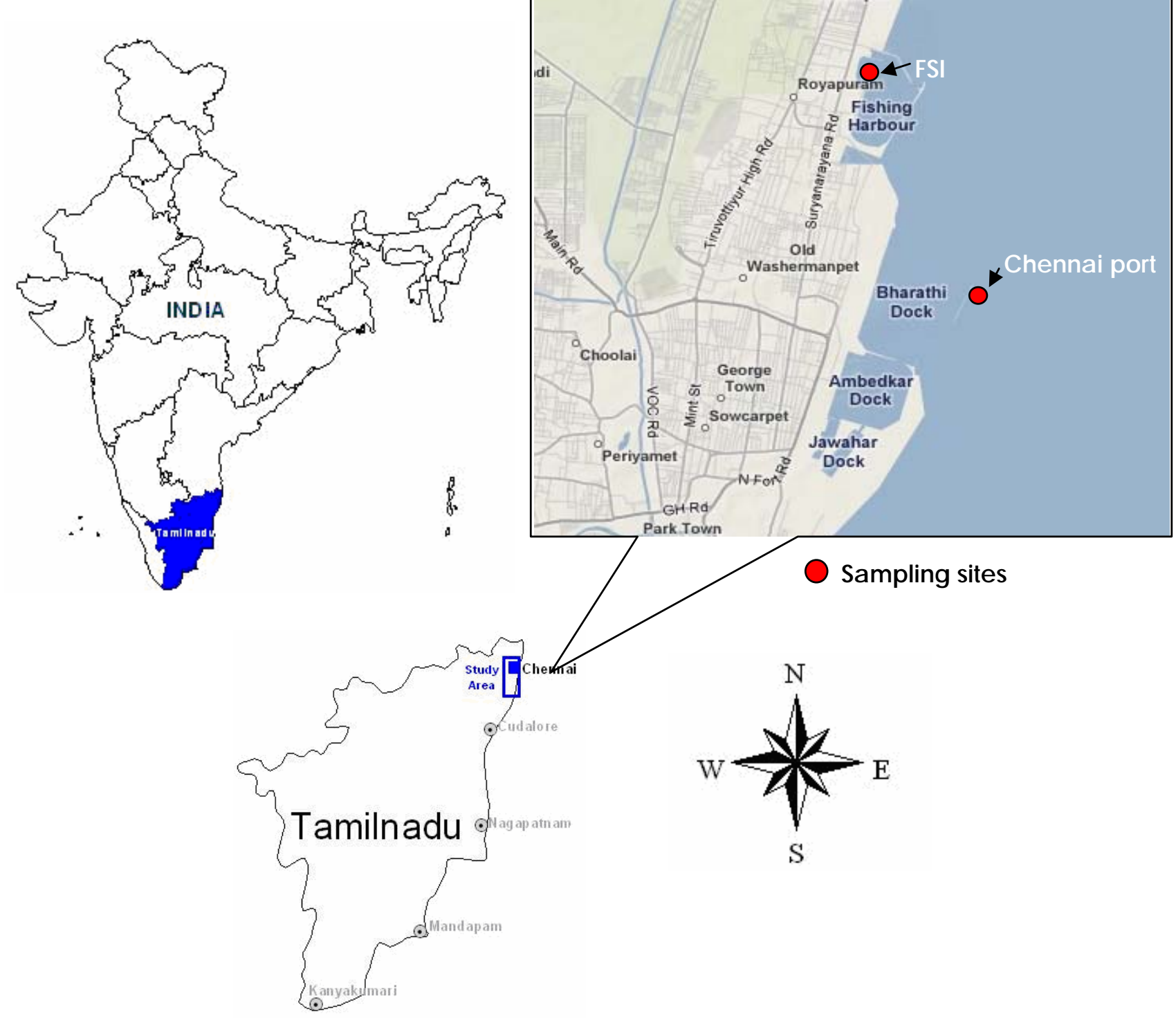

Fig. (1). Sampling locations near Fishery survey of India (FSI) and in Chennai Port along the Bay of Bengal (not to scale).

potential (ORP) at both the locations were measured every month using a Hydrolab Quanta (HACH, USA). Polymer samples, in triplicate were removed every month and analyzed.

\subsection{Biofilm Characterization}

Exposed polycarbonate coupons were retrieved from the two sites every month during the study period in sample bottles containing filtered $(0.2 \mu \mathrm{m}$, Millipore $)$ and autoclaved $\left(120^{\circ} \mathrm{C}\right.$ for $\left.15 \mathrm{~min}\right)$ sea water. Biofilm formed was scraped from the polymer surface using a nylon brush as suggested by Sharma et al. [17] and dispersed in $1500 \mathrm{ml}$ of sterile sea water. Parameters such as total suspended solids, organic carbon and chlorophyll $a$ were estimated to assess the development of biofilm on the polymer surface at both the sites since these parameters were known to hold a key role in biofouling [18, 19].

Biofilm solids were measured gravimetrically as suggested by Parsons et al. [20]. A sample of $20 \mathrm{ml}$ was filtered through a pre-ignited $\left(400^{\circ} \mathrm{C}, 4 \mathrm{hr}\right)$ and pre-weighed Whatman GF/C filter paper, dried at $100^{\circ} \mathrm{C}$ for $1 \mathrm{hr}$ and reweighed to get the dry weight of the residual biomass [19]. The photosynthetic pigment chlorophyll $a$, which represents the algae growth, was estimated from the biofilm samples based on the method reported by Parsons et al. [20]. Around $15 \mathrm{ml}$ of water sample containing scraped biofilm suspension was filtered through a $0.22 \mu \mathrm{m}$ Millipore filter paper and the filtrate was dissolved in $90 \%$ acetone. The samples were incubated for $12 \mathrm{hrs}$ at $4^{\circ} \mathrm{C}$ in the dark after which the absorbance at 630, 645, 665 and $700 \mathrm{~nm}$ was measured using a UV spectrophotometer (Perkin Elmer, Lambda 35).

Total viable counts (TVC) were estimated using Zobell's marine agar (Himedia laboratories Pvt Ltd Mumbai, India) [21]. Plates for analysis of colony forming units were prepared by spreading $100 \mu \mathrm{l}$ of sample from each bottle on Petri dish containing the selective agar. The plates were incubated in an inverted position at $30^{\circ} \mathrm{C}$, removed periodically and counted. The results presented here are mean val- 
ues of triplicate readings and the final result was expressed as colony forming units per $\mathrm{ml}\left(\mathrm{CFU} \mathrm{ml} \mathrm{m}^{-1}\right)$. The macrofoulants were removed from the polymer by cleaning the surface with $10 \%$ hydrochloric acid and then dried in hot air oven at $40^{\circ} \mathrm{C}$ for $4 \mathrm{hrs}$ before characterizing it.

\subsection{Polymer Characterization}

The changes in the chemical and surface properties of the polymer were monitored based on the following methods.

\subsubsection{Surface Wetting Properties}

Wettability of the polymer surface was determined from contact angle. It is an indication of the hydrophobicity of the surface, and higher is its value higher is the hydrophobicity. Contact angles were determined using the sessile drop method with a Camtel (Royston, UK) Goniometer (model FT200). The samples were supported on a glass slide and then analyzed. The wetting liquid used was Millipore grade distilled water. Calculations were averaged from five measurements. The drop image was processed by an image analysis system, which calculated both the left- and right contact angles from the shape of the drop with an accuracy of $\pm 0.1^{\circ}$.

\subsubsection{Surface Changes}

Scanning electron microscopy (SEM) (FEI Quanta 200) was used to detect changes in the surface morphology of the polymer due to degradation or deterioration. Nearly $10 \mathrm{~mm} \times$ $10 \mathrm{~mm}$ piece was cut from the polymer sample and placed on the sample holder of the SEM. Environmental mode was used for scanning the surface of the polymer as it is nonconducting in nature. The samples were scanned within an area of $20 \mu \mathrm{m}^{2}$ at a magnification of $2000 \times$.

Atomic force microscopy (AFM) was used to determine the surface topography and roughness of the polymer coupons that were exposed to the sea water. The sample was mounted on a piezoelectric scanner and the surface was scanned within an area of $10 \mu \mathrm{m}^{2}$ with a silicon nitride cantilever. The analysis was performed on a Nanoscope III AFM microscope with an ADCS controller in contact mode.

\subsubsection{Thermal Analysis - Differential Scanning Calorime- try}

Differential scanning calorimetry (DSC) was performed using a NETZCH Phoenix DSC-7 apparatus, calibrated with indium standard. To determine the glass transition temperature, scans were carried out at a heating rate of $10^{\circ} \mathrm{C} \mathrm{min}^{-1}$ under nitrogen atmosphere. The samples were analyzed over a temperature range of 50 to $300^{\circ} \mathrm{C}$ using heating and cooling cycles. Weight of the samples loaded varied from 5 to 7 $\mathrm{mg}$.

\subsubsection{Thermal Analysis - Thermo Gravimetric Analysis}

Thermo gravimetric analysis (TGA) was carried out with a simultaneous thermal analyzer STA 409 (NETZSCH, USA). Sample of about $20 \mathrm{mg}$ was heated under nitrogen atmosphere at a flow rate of $40 \mathrm{ml} \mathrm{min}^{-1}$ and at a heating rate of $10 \mathrm{~K} \mathrm{~min}^{-1}$. Ceramic sample pans with alumina were used as the reference material. The onset temperature $\left(T_{0}\right)$ (i.e. temperature at which decomposition is initiated) was determined by the tangent method. Onset and end point of decomposition were calculated as intersections between base line and tangent at the inflection point using the NETZSCH
TA WINDOWS ${ }^{\mathrm{TM}}$ PROTEUS $^{\circledR}$ data analysis software. The inflection point was determined from DTG curve (derivative of TG). The loss in weight over a specific temperature range provided an indication of the integrity of the sample.

\subsubsection{Fourier Transforms Infrared Spectroscopy}

Fourier transform infrared (FTIR) spectra, which is used for detecting the formation of new functional groups or change in the amount of existing functional groups, were recorded on a Jasco N4200 spectrometer at a resolution of 4 $\mathrm{cm}^{-1}$ in the frequency range of 4000 to $400 \mathrm{~cm}^{-1}$, calibrated with polystyrene standards. The analysis was performed using HATR (Horizontal Attenuated Total Reflectance) mode by accumulating 32 scans. The readings were taken in triplicates and the mean and standard deviation are presented. The methyl index was calculated by taking the ratio of absorbance at 2915 and $1508 \mathrm{~cm}^{-1}$. The former peak corresponds to the stretching frequency of methyl carbon, while the later peak corresponds to bending frequency of aromatic $\mathrm{sp}^{2}$ carbon. This latter peak is assumed to be the internal standard, since it is reported that the phenyl stretching vibrations are not affected significantly even under strong ionic irradiation [22]. In order to differentiate the peaks from noise, the FTIR spectra were deconvoluted using the JASCO spectra analysis software. Carbonate carbonyl index (CC index) (ratio of carbonate bond at $1778 \mathrm{~cm}^{-1}$ to aromatic $\mathrm{CH}$ stretching at 1508 $\mathrm{cm}^{-1}$ ) was calculated using two-point base method [23]. This method would eliminate the error that would occur during baseline correction.

\subsubsection{Mechanical Properties}

The tensile strength of the samples were measured in triplicate as per the ASTM D638 procedure [24] (which measures the stress-strain characteristics of rigid plastics with a thickness greater than $1 \mathrm{~mm}$ ) on an Instron machine (model 4204 ) at $30^{\circ} \mathrm{C}, 50 \%$ humidity and a cross-head speed of $50 \mathrm{~mm} \mathrm{~min}^{-1}$.

\section{RESULTS AND DISCUSSION}

Photographs of polycarbonate samples retrieved from the sea are shown in Fig. (2). The extent of biofouling on the polycarbonate varied with duration of exposure.

The photographs also revealed the presence of macrofoulants, which were seen more clearly after the removal of the soft fouling material by scraping the surface with the nylon brush (Fig. 2b). The macrofoulants such as barnacles remained strongly attached to the surface of the polymer for a long period of time. The nature of biofouling at port and FSI appeared to be different (Fig. 2c, d).

Sea water parameters provide information on the biodegradation environment for the present study [25]. The average water quality parameters at the two sites during the course of the study (namely from March to August 2006) are listed in Table 1. Dissolved oxygen (DO) and oxidation and reduction potential (ORP) are significantly less at FSI when compared to Port. ORP is an indication of the effect of aeration on the seawater and is a measure of the oxidation potential of the medium. ORP increases with decreasing $\mathrm{pH}$ [26]. Dissolved oxygen in the seawater is significantly influenced by physical and biological processes such as, fresh water influx, water mass transport, photosynthesis and respiration [27]. The 


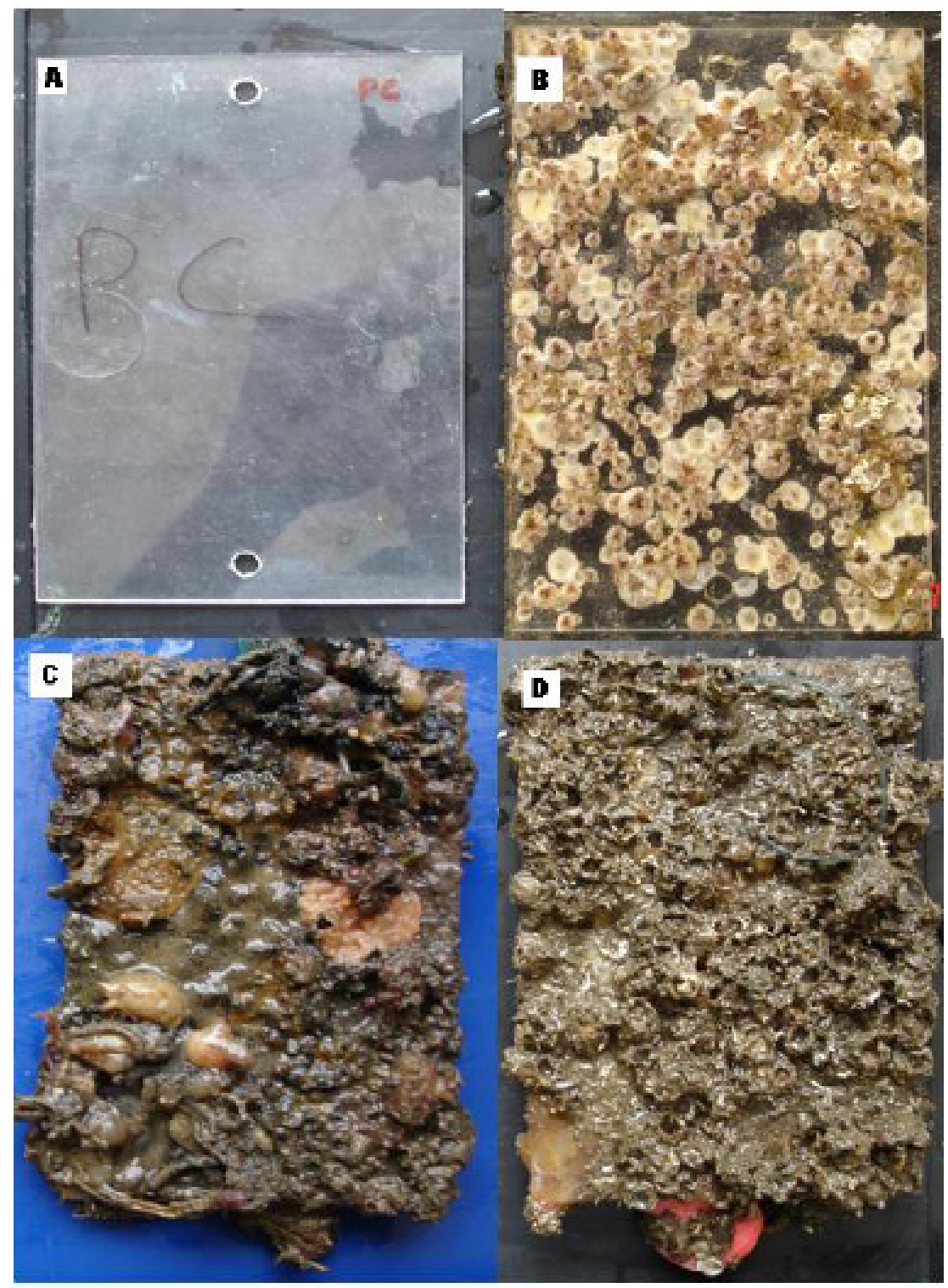

Fig. (2). (A) Polycarbonate coupon control sample (B) after the slime was scraped at Port after six months (C) and (D) Polycarbonate coupon immersed in sea water at Port and FSI after six months respectively.

lower DO and ORP levels in FSI could be due to its location closer to the shore and higher anthropogenesis, whereas port is away from the sea shore and geographically facing the open sea, leading to a continuous circulation of fresh seawater. The accumulation of biofilm solids and organic matter on the polymer at both the sites as a function of time are shown in Fig. (3a, b) respectively.

Table 1. Average Water Quality Parameters at FSI and Port during the Study Period

\begin{tabular}{|c|l|c|c|}
\hline S. No & \multicolumn{1}{|c|}{ Parameter } & FSI & PORT \\
\hline \hline 1 & Temperature $\left({ }^{\circ} \mathrm{C}\right)$ & $29 \pm 1.5$ & $30 \pm 4.5$ \\
\hline 2 & Dissolved oxygen $\left(\mathrm{cm}^{3} \mathrm{dm}^{-3}\right)$ & $3.39 \pm 0.2$ & $4.82 \pm 0.2$ \\
\hline 3 & $\mathrm{pH}$ & $8 \pm 0.2$ & $7.8 \pm 0.3$ \\
\hline 4 & Salinity (ppt) & $32 \pm 1.5$ & $33 \pm 1.5$ \\
\hline 5 & $\begin{array}{l}\text { Oxidation \& Reduction } \\
\text { potential (ORP) }(\mathrm{mV})\end{array}$ & $84 \pm 20$ & $120 \pm 30$ \\
\hline
\end{tabular}

The total suspended solids, organic matter and total viable counts are generally higher at Port than at FSI. The average amount of biofilm deposited per month on PC was $4 x$ $10^{-2} \mathrm{mg} \mathrm{cm}^{-2}$. Total suspended solids contain both organic and inorganic substances in the biofilm. The biofouling and organic matter are lower at FSI than at Port, which is probably due to lower DO at the former site, while highest at both the sites in the month of August probably due to the termination of the South West monsoon and commencement of North East Winds leading to changes in ocean currents in Bay of Bengal. The major contributors for the organic carbon in the biofilm are TVC and chlorophyll $a$ [19]. It is observed that contribution by TVC is high towards organic carbon in the first month at port whereas the contribution by chlorophyll $a$ dominates at FSI in the first month.

The amount of chlorophyll $a$ (Fig. 4) was generally more at FSI when compared to that at the Port (except in the 


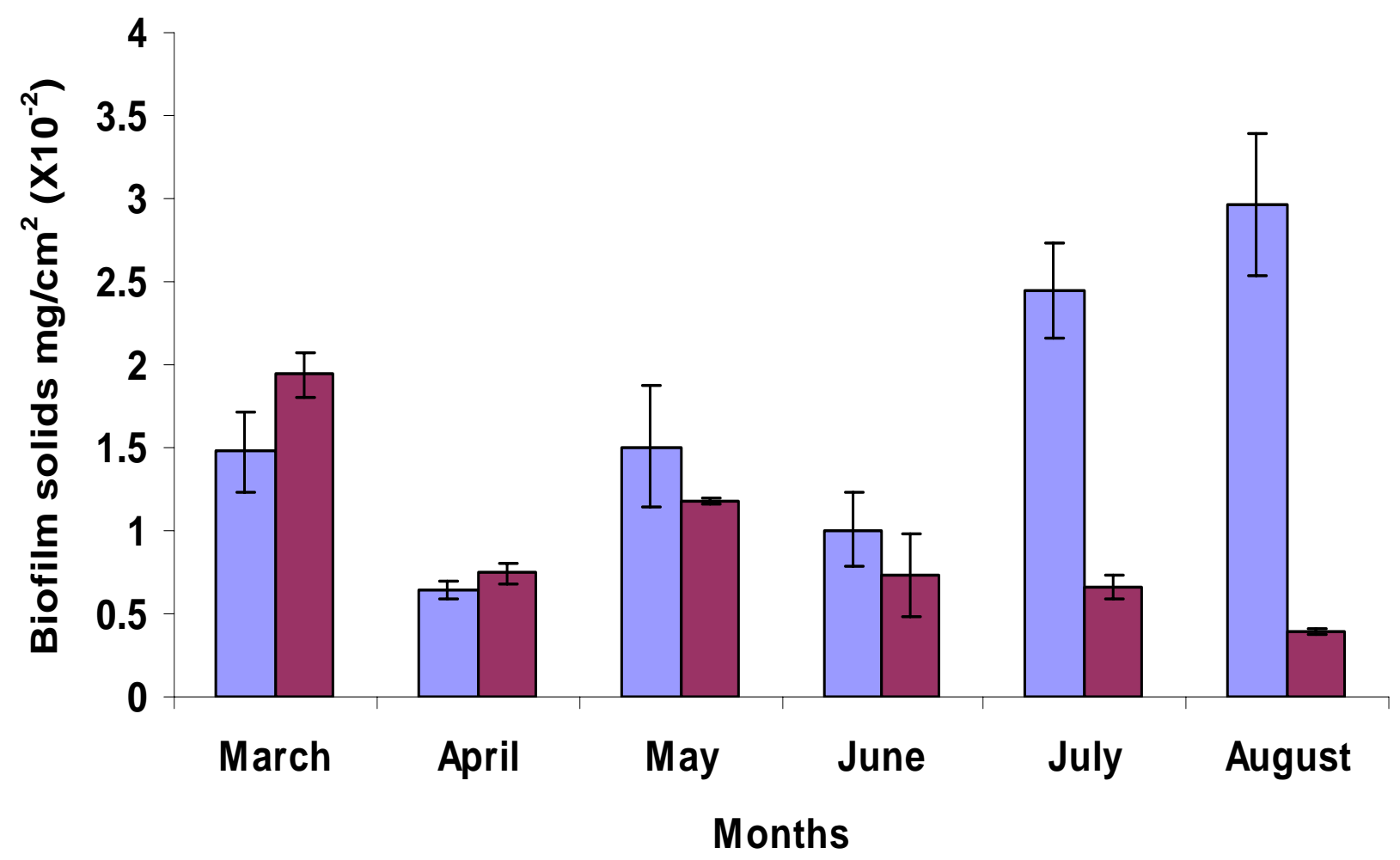

Fig. (3a). Biofilm settlement in terms of total suspended solids on PC at both locations ( $\square$ Port, $\square$ FSI).

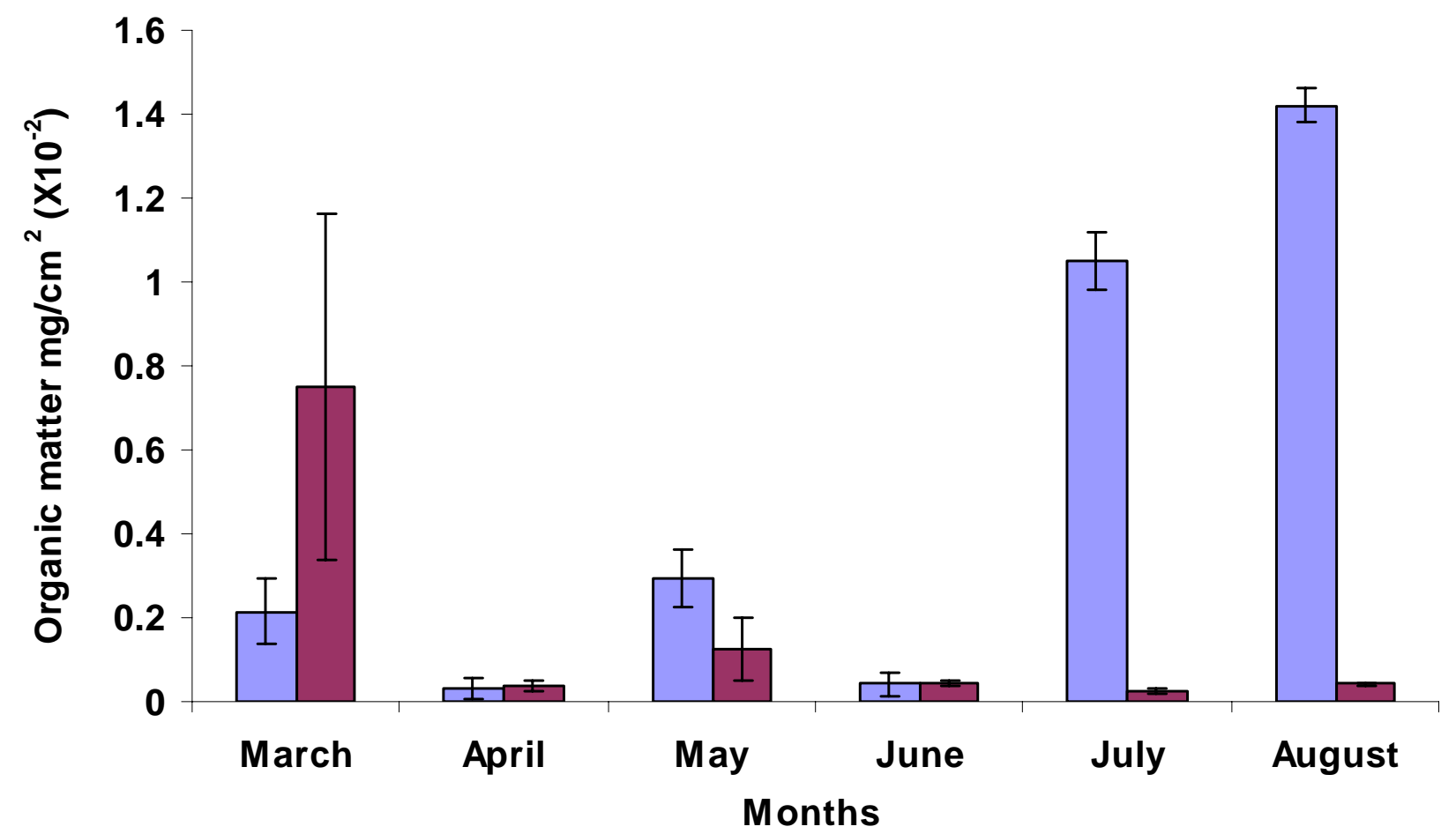

Fig. (3b). Cumulative organic matter or organic carbon on PC at both locations ( $\square$ Port, $\square$ FSI). 


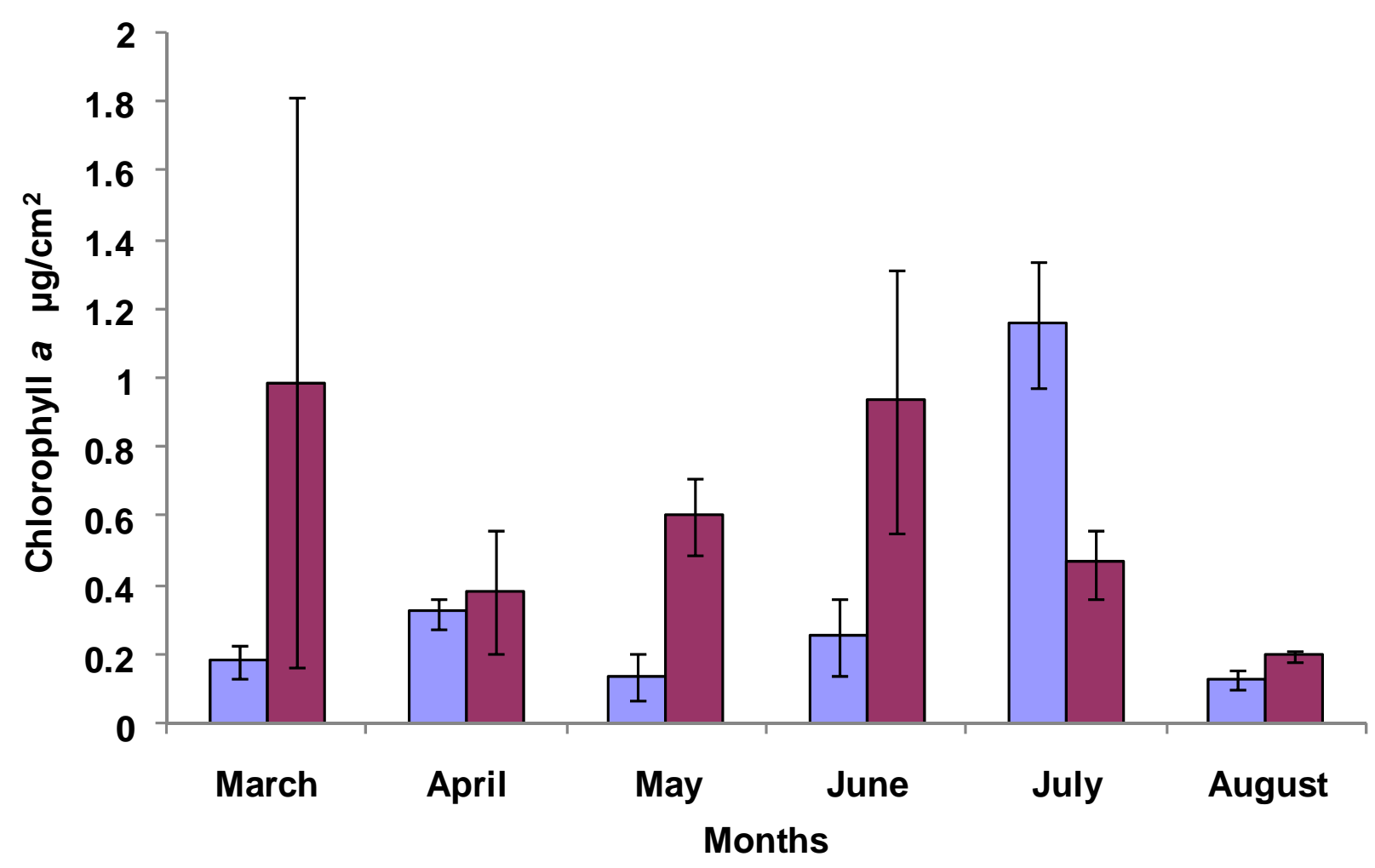

Fig. (4). Cumulative photosynthetic Chlorophyll $a$ pigment in the biofilm on PC at ( $\square$ Port, $\square$ FSI).

month of July). Both autotrophs and heterotrophs contribute to the organic matter in the biofilm. Chlorophyll $a$ (seaweed and algae) is an indication of the abundance of the autotrophs in the biofilm. The micro algal growth was highest in the month of July at Port. Previous workers [20, 26] observed that water pollution leads to higher chlorophyll formation. This is also confirmed by higher chlorophyll $a$ at FSI which in turn leads to a higher utilization of dissolved oxygen for their growth [28].

Cumulative total viable count (TVC) is higher at Port than at FSI (Fig. 5).

The total viable count at both the sites did not show any pattern. The average TVC (over the six month period) at Port is as high as $35000 \mathrm{CFU} \mathrm{ml}{ }^{-1}$, while it is $17000 \mathrm{CFU} \mathrm{ml}^{-1}$ at FSI. It was observed that cumulative total viable counts at FSI were lower than at Port through out the study except for the month of May. The higher DO at Port favors the development of aerobic epilithic bacteria and the metabolism of these microorganisms can lead to the biodegradation process [29]. Even though the water quality parameters look relatively consistent, the observed poor correlation on the biofilm solids among the months could be due to the varying thickness of biofilm which gets dislodged from time to time due to excess settlement of macrofoulers or due to ocean currents [30]. Apart from barnacles, other foulants like mus- sels, tube worms and hydroids were also found however, their relative amount varied from one month to the other. In the present study the thickness and number of macrofoulers were not quantified.

The degradation of the polymer manifested itself in various ways. Chemical, physical and mechanical changes occurred during the process and they were monitored by various techniques as listed in section 2.4. It is already known that during the formation of biofilm an interaction takes place between the substratum and the bacterial communities. Contact angle for the port sample reduced by $33 \%$ when compared to the control sample (Table 2) indicating an increase in surface hydrophilicity. This indicates a chemical change at the surface of the polymer. From the current study and earlier studies on polyolefins [9] it is observed that deposition of biofilm solids is substrate specific and is dependant on the hydrophobicity (contact angle) of the substrate (Table 3). Higher the surface hydrophobicity, higher is the biofilm settlement.

Fig. (6) presents the AFM images of the polycarbonate samples before and after exposure to sea water for a period of six months. The control sample (Fig. 6a) had a root mean square surface roughness of $9.39 \mathrm{~nm}$ and the samples retrieved from port after one month of deployment (Fig. 6b) showed a surface roughness of $238.55 \mathrm{~nm}$. The six months 


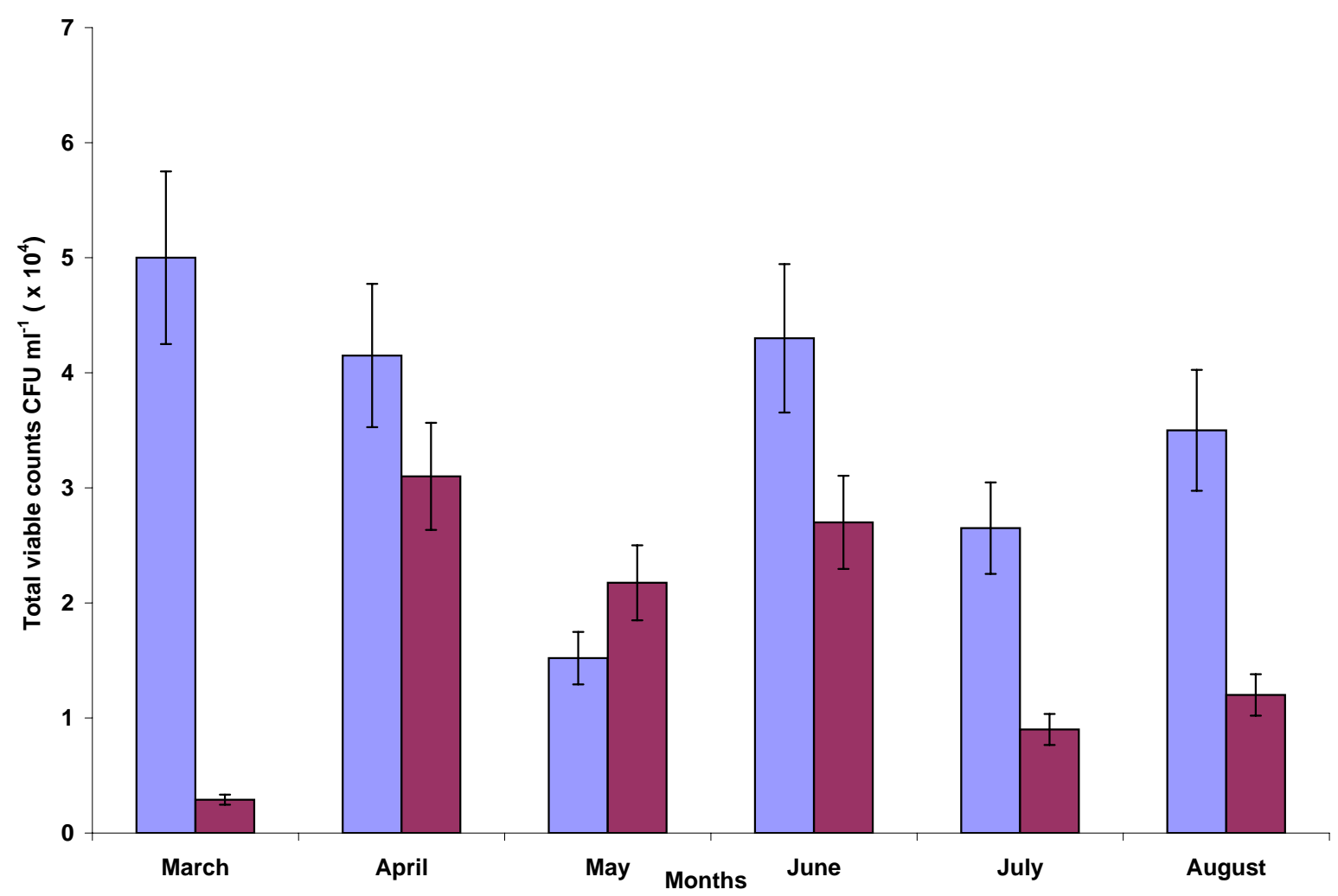

Fig. (5). Total viable counts (Zobell's marine agar) on PC surface at both the sites ( $\square$ Port, $\square$ FSI).

Table 2. Physiochemical Analysis of The Polycarbonate Samples after Six Months at Port and FSI

\begin{tabular}{|c|c|c|c|c|c|c|c|}
\hline & \multicolumn{2}{|c|}{ DSC } & \multirow{2}{*}{ Tensile Strength } & \multicolumn{2}{|c|}{ TGA $\left({ }^{\circ} \mathbf{C}\right)$} & \multirow{2}{*}{ Contact Angle } \\
\cline { 2 - 4 } & $\mathbf{T}_{\mathbf{g}}\left({ }^{\circ} \mathbf{C}\right)$ & $\mathbf{T}_{\mathbf{m}}\left({ }^{\circ} \mathbf{C}\right)$ & $\mathbf{N m m}^{-2}$ & & $\mathbf{T}_{\mathbf{o}}$ & \multirow{2}{*}{ Inflection Point } & \\
\hline \hline Control & 133.1 & 243.3 & 18.4 & 6.05 & 409.5 & 425.6 & $78.89^{\circ}$ \\
\hline Port & 146.9 & 243.1 & 8.86 & 12.75 & 413.4 & 433.9 & $52.67^{\circ}$ \\
\hline FSI & 143.5 & 242.8 & 8.42 & 10.3 & 411.7 & 432.6 & $70.93^{\circ}$ \\
\hline
\end{tabular}

port (Fig. 6c) and FSI (Fig. 6d) samples had a surface roughness of $451.47 \mathrm{~nm}$ and $358.30 \mathrm{~nm}$ respectively. It is observed that surface directly under a barnacle deposition showed a roughness of only $13.01 \mathrm{~nm}$ even after six months as against a six months average value of $451.47 \mathrm{~nm}$. The increase in surface roughness could also be due to the settlement of macrofoulers leading to leaching and degradation of the sample. Scanning electron micrograph pictures of the samples are shown in Fig. (7).

The pictures clearly indicate erosion and pitting of the surface due to the biodegradation or biodeterioration caused by micro and macrofoulers. The thermograms from differential scanning calorimetry (DSC) indicates a rise in glass transition temperature $\left(\mathrm{T}_{\mathrm{g}}\right)$ in both the Port and FSI six months samples when compared to the control (from $133.1^{\circ} \mathrm{C}$ to $146.9^{\circ} \mathrm{C}$ and $143.5^{\circ} \mathrm{C}$ respectively) (Table 2). An increase in glass transition temperature can rise due to the conformational changes in the polymer molecule leading to a decrease in its mobility or due to loss of the amorphous region in the polymer. Generally, degradation starts in the amorphous
Table 3. Correlation Between Contact Angle and Average Biofilm Solids Attachment after Six Months

\begin{tabular}{|c|c|c|c|}
\hline Polymer & & Contact Angle & $\begin{array}{c}\text { Biofilm Solids }(\mathbf{m g . c m} \\
\times \mathbf{1 0}^{-2}\end{array}$ \\
\hline \hline LDPE $^{\dagger}$ & Control & $58.0^{\circ}$ & \\
& PORT 6M & $66.7^{\circ}$ & 0.11 \\
& FSI 6M & $61.1^{\circ}$ & 0.07 \\
\hline HDPE $^{\dagger}$ & Control & $63.1^{\circ}$ & \\
& PORT 6M & $68.6^{\circ}$ & 0.10 \\
& FSI 6M & $65.2^{\circ}$ & 0.08 \\
\hline PP $^{\dagger}$ & Control & $64.3^{\circ}$ & \\
& PORT 6M & $65.2^{\circ}$ & 0.11 \\
& FSI 6M & $64.6^{\circ}$ & 0.07 \\
\hline PC & Control & $78.89^{\circ}$ & 2.96 \\
& PORT 6M & $52.67^{\circ}$ & 0.40 \\
\hline & FSI 6M & $70.93^{\circ}$ & \\
\hline
\end{tabular}




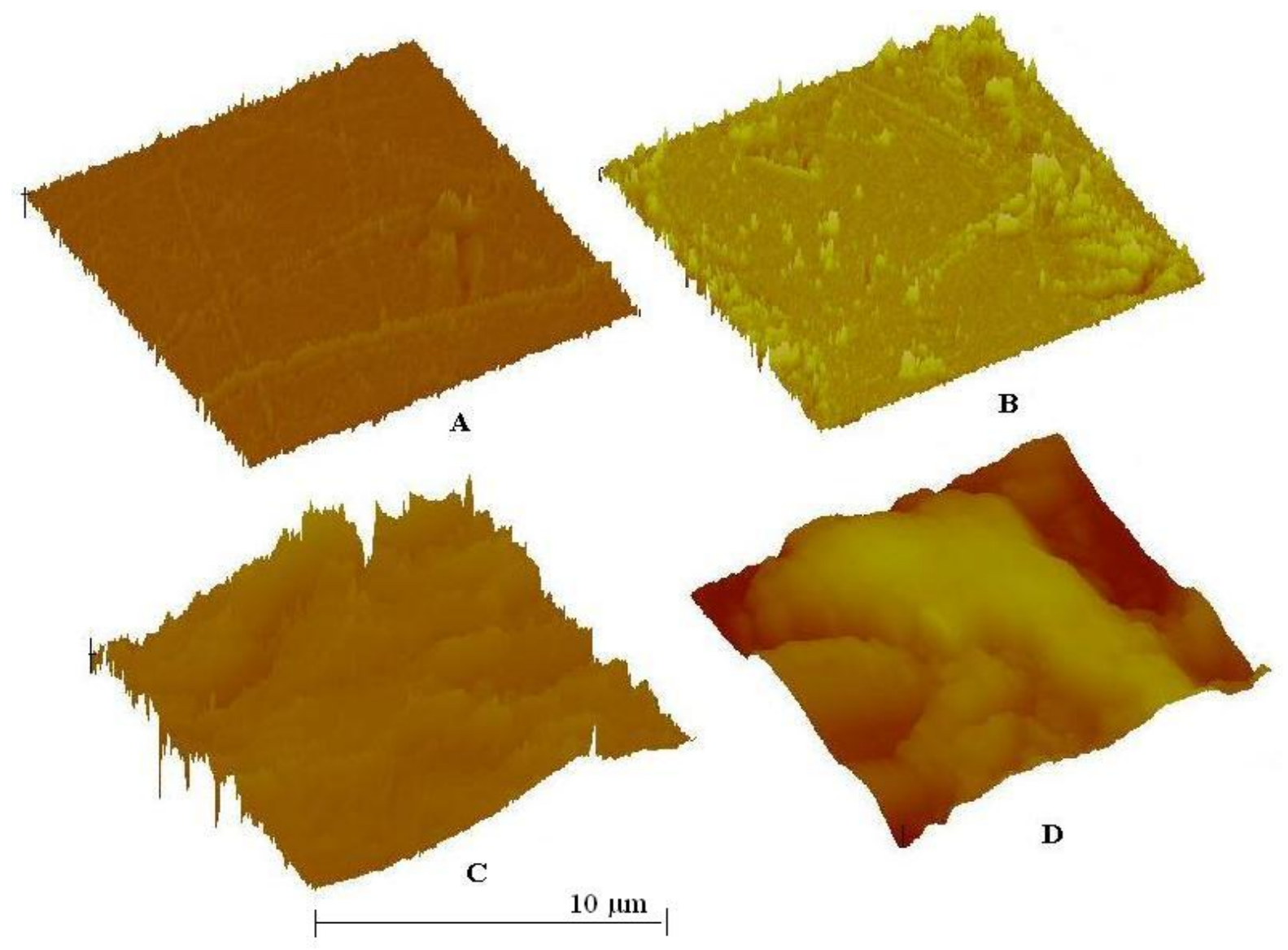

Fig. (6). AFM images of the PC samples (A) control, (B) at Port after 1 month (C) and (D) at Port and FSI after six months respectively.

region of the polymer which can lead to an initial increase in the crystallinity [31]. Even though there is not much difference in their melting points $\left(\mathrm{T}_{\mathrm{m}}\right)$, a considerable change in the melting enthalpies is observed between FSI and Port samples $\left(\Delta \mathrm{H}=43.86\right.$ and $38.89 \mathrm{~J} \mathrm{~g}^{-1}$ respectively). The control polycarbonate sample has a melting enthalpy of $\Delta \mathrm{H}=44.26 \mathrm{~J} \mathrm{~g}^{-1}$. TGA investigations under nitrogen atmosphere demonstrate increase in onset temperature $\left(\mathrm{T}_{\mathrm{o}}\right)$ and inflection points for samples from field with respect to the control sample (Table 2). These results are in concurrence with the DSC data.

The tensile strength of the polycarbonate has drastically reduced by nearly $50 \%$ in six months for the samples at FSI and port. As expected there is an increase in the percentage elongation when compared to the control sample. The high reduction in tensile strength indicates that the polycarbonate has lost its mechanical integrity and can be attributed to the combined action of microorganisms, macrofouling and ocean currents.

In the FTIR spectra of polycarbonate (Fig. 8) the intensity of the methyl group at $2915 \mathrm{~cm}^{-1}$ in PC has reduced in port and FSI samples when compared to the control. The methyl index decreased from 0.70 (for control) to 0.29 and
0.34 for port and FSI samples respectively. The deconvoluted FTIR spectra (inset in Fig. 8) clearly show marked differences between the control and six month samples. In the current study the $\mathrm{CC}$ index decreased from a value of 0.45 (control) to 0.30 and 0.17 for samples at Port and FSI respectively. Variation in the organic group indices was clearly observed during the period of the study (Table 4).

The changes in the FTIR spectra are solely because of biodegradation since deterioration cannot bring about changes in the functional groups in the polymer. Schmidt et al. [32] has suggested that polycarbonate contains conformationally sensitive IR bands namely carbonate carbonyl $\left(1775 \mathrm{~cm}^{-1}\right)$, phenyl $\mathrm{C}=\mathrm{C}$ stretching and $\mathrm{C}-\mathrm{O}-\mathrm{C}$ skeletal vibrations $\left(1260 \mathrm{~cm}^{-1}\right)$ which change during degradation. Changes in the carbonyl region of polycarbonate spectrum are observed in the current study indicating biodegradation. A reduction in the methyl index indicates the oxidation of the tertiary methyl group on Bisphenol A polycarbonate. Under biological conditions this reaction is catalyzed by oxidoreductases. If hydrolases like lipase act upon polycarbonate, then carboxylic acids with a peak around $1730 \mathrm{~cm}^{-1}$ and phenolic $\mathrm{OH}$ groups with a broad peak around $3200 \mathrm{~cm}^{-1}$ should have been observed in the FTIR spectrum, which were not detected here. Based on dissociation energies of various bonds in PC it could be as- 


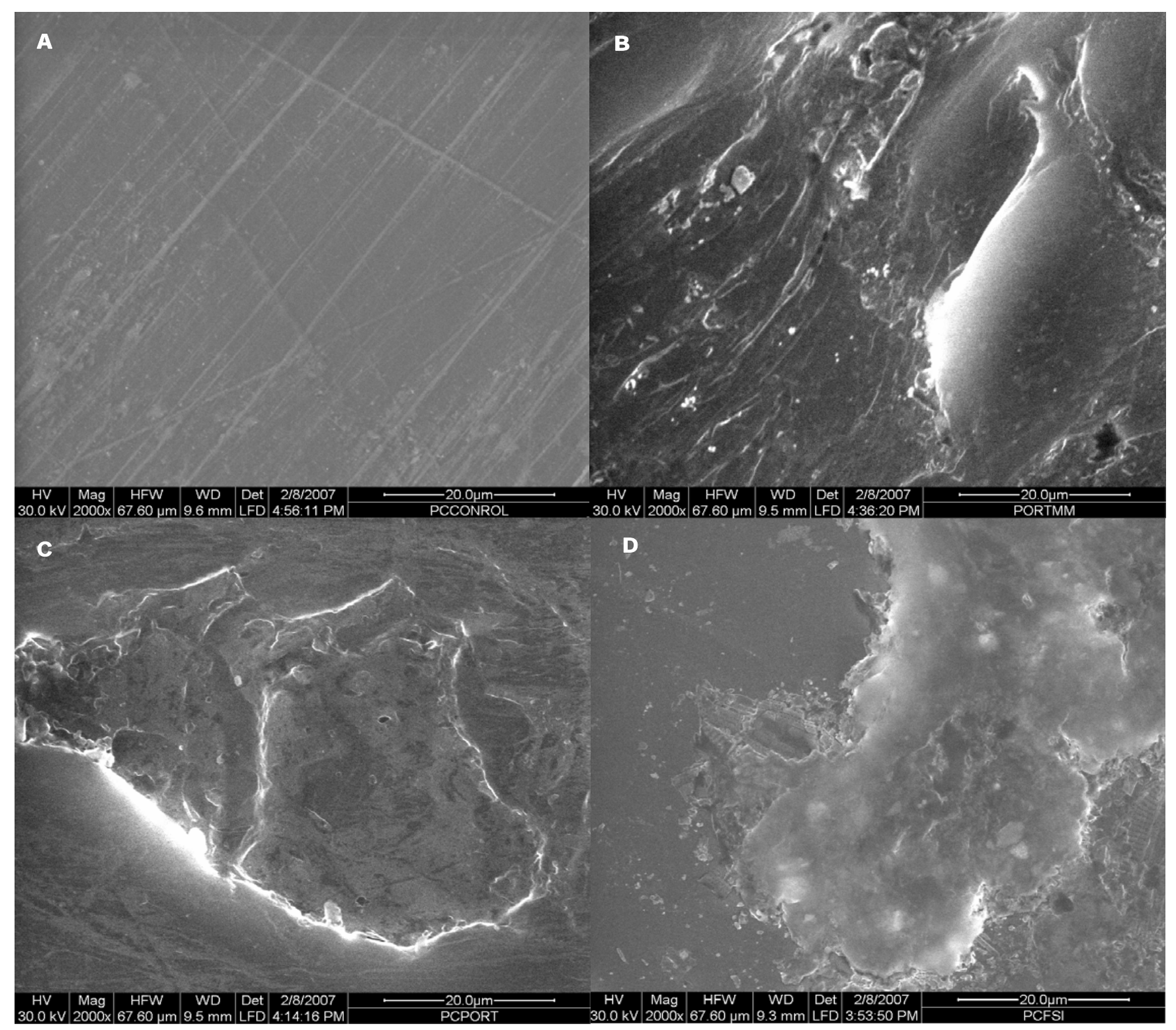

Fig. (7). Scanning electron micrograph pictures of the polymer samples (A) control, (B) at Port after 1 month (C) and (D) at Port and FSI after six months respectively.

sumed that the degradation of polycarbonate could involve chain scission of the isopropylidene linkage (bond energy of $251 \mathrm{~kJ} \mathrm{~mol}^{-1}$ ), and hydrolysis/alcoholysis of the carbonate linkage (bond energy of $330 \mathrm{~kJ} \mathrm{~mol}^{-1}$ ). Jang and Wilkie [33] reported that when polycarbonate undergoes oxidation, peroxides are formed. These peroxides can further undergo, at the early stages of degradation, dissociations and combinations, producing mainly aldehydes, ketones and some branched structures. Rivaton [34] reported that the phenyl radicals react with the polycarbonate by abstracting $\mathrm{H}$ atoms from the methyl groups and induce the cleavage of the $\mathrm{Me}_{2} \mathrm{C}-\mathrm{C}_{6} \mathrm{H}_{5}$ and $\mathrm{C}(\mathrm{O})-\mathrm{O}$ bonds. Since there is higher dissolved oxygen at Port it is understandable that the oxidative degradation is higher here when compared to FSI.

\section{CONCLUSION}

In the current study polycarbonate samples are immersed in tropical sea water at two different locations and the extent of biofouling and biodegradation of the polymer are monitored by measuring the physical, mechanical, and chemical changes to the samples. The quantity of the dissolved oxygen plays an important role in the extent of biofouling and attachment of microorganisms. Higher the DO higher is the biofouling. Chlorophyll pigmentation is inversely proportional to DO levels in the water. Considerable increase in $\mathrm{T}_{\mathrm{g}}$ and $\mathrm{T}_{\mathrm{o}}$ are observed on samples indicating a change in chain mobility. AFM analysis indicates a forty to fifty times increase in surface roughness of the exposed samples. Tensile strength decreased from 18 to $8 \mathrm{Nmm}^{-2}$ during the study period. The changes in the carbonate carbonyl and methyl indices indicate that the polymer undergoes biodegradation, 


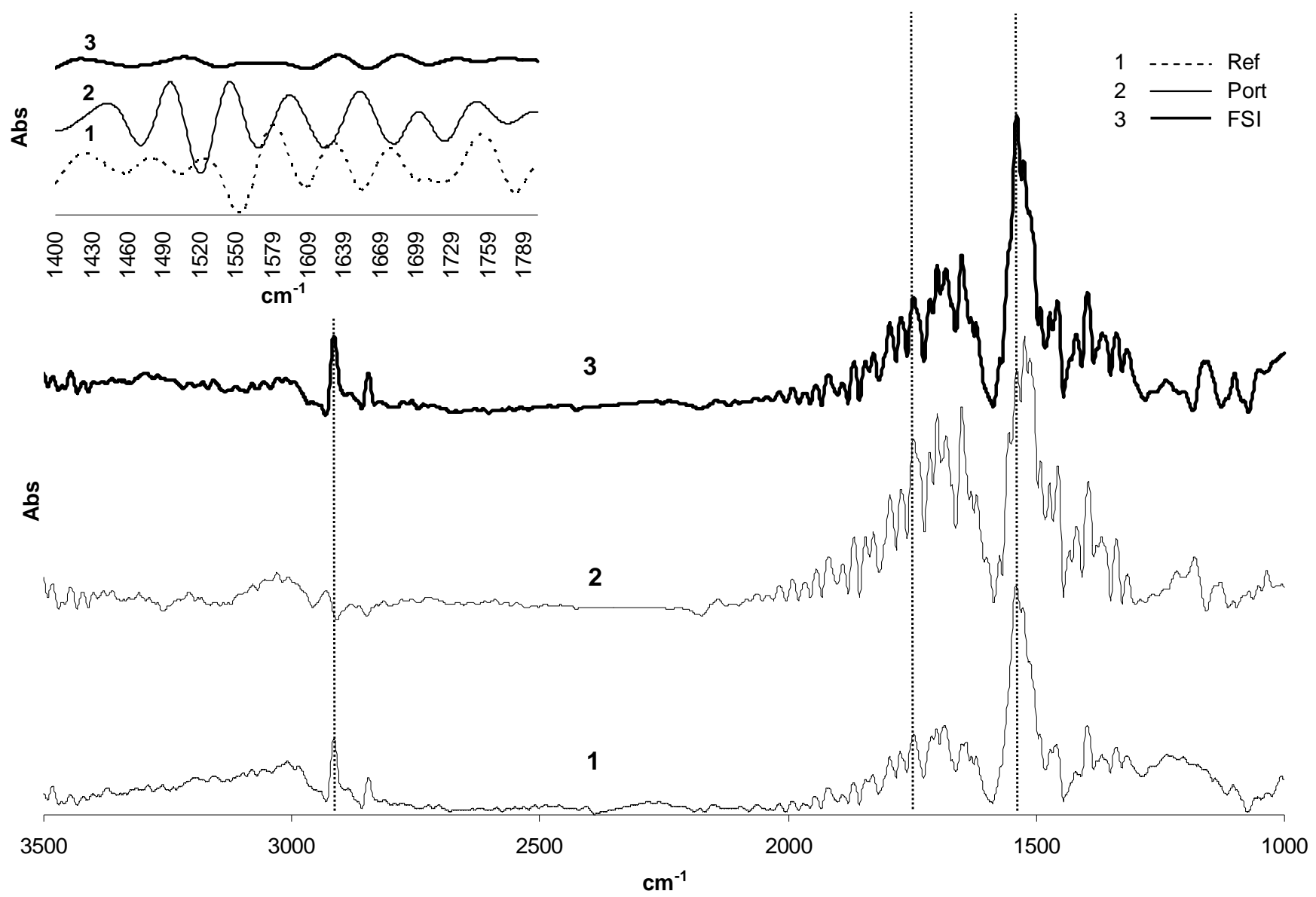

Fig. (8). FTIR spectra of control, port and FSI samples after six months. (Deconvoluted spectra shown in inset).

probably catalyzed by oxidoreductases. The current study has shown that biological analysis in lieu with chemical analysis is necessary for the complete understanding of the degradation process as the rates of biodegradation will vary tremendously depending on the environment selected for the exposures, and every environment used will be different. Therefore, it will be impossible to standardize methodologies and compare with literature.

Table 4. Carbonyl Carbon (CC) Index and Methyl Index (MI) Variation at Port and FSI during the 6 Months Study

\begin{tabular}{|c|c|c|}
\hline Months & $\mathbf{C C} \pm(\mathbf{S D})$ & $\mathbf{M I} \pm(\mathbf{S D})$ \\
\hline \hline Control & $0.45 \pm 0.06$ & $0.70 \pm 0.17$ \\
\hline Port $2 \mathrm{M}$ & $0.36 \pm 0.14$ & $0.53 \pm 0.25$ \\
\hline Port 4M & $0.35 \pm 0.10$ & $0.42 \pm 0.12$ \\
\hline Port 6M & $0.30 \pm 0.04$ & $0.29 \pm 0.14$ \\
\hline FSI 2M & $0.44 \pm 0.02$ & $0.65 \pm 0.17$ \\
\hline FSI 4M & $0.41 \pm 0.20$ & $0.34 \pm 0.01$ \\
\hline FSI 6M & $0.17 \pm 0.04$ & $0.34 \pm 0.08$ \\
\hline
\end{tabular}

\section{ACKNOWLEDGEMENTS}

Authors thank sophisticated analytical instrumentation facility and metallurgy department of IIT Madras, Chennai, for DSC and SEM analysis, and Director, NIOT for permitting us to use their analytical facilities.

\section{REFERENCES}

[1] Lin, C. H.; Lin, H.Y.; Liao, W.Z.; Dai, S.A. Novel chemical recycling of polycarbonate (PC) waste into bis-hydroxyalkyl ethers of bisphenol A for use as PU raw materials. Green Chem., 2007, 9, 38-43.

[2] Artham, T.; Doble, M. Biodegradation of aliphatic and aromatic polycarbonates. Macromol. Biosci., 2008, 8(1), 14-24.

[3] Sivalingam, G.; Madras, G. Dynamics of lipase catalyzed enzymatic degradation of poly(bisphenol-A carbonate). J. App. Polym. Sci., 2004, 91, 2391-2396.

[4] Sajiki, J.; Yonekubo, J. Leaching of bisphenol A (BPA) to seawater from polycarbonate plastic and its degradation by reactive oxygen species. Chemosphere, 2003, 51, 55-62.

[5] Kang, J-H.; Katayama, Y.; Kondo, F. Biodegradation or metabolism of bisphenol A: From microorganisms to mammals. Toxicology, 2006, 217, 81-90.

[6] Maria, R.; Katarzyna, K.; Aleksandra, H.; Izabela, S.; Helena, J. Degradation of polyurethanes in sea water. Polym. Degrad. Stabil., 2002, 76(2), 233-239.

[7] Rutkowska, M.; Heimowska, A.; Krasowska, K.; Janik, H. Biodegradability of Polyethylene Starch Blends in Sea Water. Pol. J. Environ. Stud., 2002, 11(3), 267-274.

[8] Yoshiharu, D.; Youko, K.; Naoki, T.; Yoshiharu, K. Biodegradation of microbial polyesters in the marine environment. Polym. Degrad. Stabil., 1992, 36(2), 173-177. 
[9] Sudhakar, M.; Trishul, A.; Doble, M.; Kumar, K.S.; Jahan, S.S.; Inbakandan; Viduthalai, R.R.; Umadevi, P.; Murthy, P.S.; Venkatesan, R. Biofouling and biodegradation of polyolefins in ocean waters. Polym. Degrad. Stabil., 2007, 92(9), 1743-1752.

[10] Barbiero, R.P. A multi-lake comparison of epilithic diatom communities on natural and artificial substrates. Hydrobiologia, 2000, 438, 157-170.

[11] Danilov, R.A.; Ekelund, N.G.A. Comparison of usefulness of three types of artificial substrata (glass, wood and plastic) when studying settlement patterns of periphyton in lakes of different trophic status. J. Microbiol. Methods, 2001, 45, 167-170.

[12] Bohuss, I.; Rekasi, T.; Szikora, S.; Barkacs, K.; Zaray, G.; Acs, E. Interaction of acetochlor and atrazine with natural freshwater biofilms grown on polycarbonate substrate in Lake Velence (Hungary). Microchem. J., 2005, 79(1-2), 201-205.

[13] Zaray, G.; Kroepfl, K.; Szabo, K.; Taba, G.; Acs, E.; Berlinger, B.; Dogan, M.; Salih, B.; Akbulut, A. Comparison of freshwater biofilms grown on polycarbonate substrata in Lake Velence (Hungary) and Lake Mogan (Turkey). Microchem. J., 2005, 79(1-2), 145-148.

[14] West, T.; Daniel, P.; Labonte, J.; DeGraca, A.; Boozarpour, M.; Chemlick, D.; Hou, S. The effects of ozone and chloramination on distribution system regrowth. In Proceedings of Annual Conference of American Water Works Association, American Water Works Association, (Vol. D, Water Quality), USA, 1998, pp. 619-639.

[15] Fonseca, A.C.; Greenberg, A.R.; Hernandez; Mark, T. Biofouling of nanofiltration membranes - detection using ultrasonic frequencydomain reflectometry (UFDR). In Proceedings of the Annual Conference of American Water Works Association, American Water Works Association, USA, 2003, pp. 632-638.

[16] Krisztina, K.; Peter, Vladar.; Katalin, S.; Ėva, A.; Andrea, K.B.; Szilvia, S.; Sergio, C.; Gyula, Z. Chemical and biological characterisation of biofilms formed on different substrata in Tisza river (Hungary). Environ. Pollut., 2006, 144, 626-631.

[17] Sharma, M.O.; Bhogle, N.; Wagh, A.B. Methods for the removal and estimation of microfouling biomass. Indian J. Mar. Sci., 1990, 19, 174-176.

[18] Bhosle, N.B.; Nandakumar, K.; Dhople, V.M.; Sawant, S.S.; Wagh, A.B.; Kelkar, P.G. Biological and biochemical characterization of microfouling on aluminum panels placed in the Arabian sea. In Proceedings of the Indian National Science Academy B.; India, 1989, 55, pp. 51-56.

[19] Bhosle, N.B. Chemical and Molecular Characterization of Biofilm on Metal Surfaces. In Marine Microbiology: Facets and Opportunities. National Institute of Oceanography, Goa, 2005, pp.159-168.
[20] Parsons, T.; Maita, Y.; Lalli, C.M. A Manual of Chemical and Biological Methods for Seawater Analysis, Pergamon Press, New york. 1984, pp.173.

[21] Murthy, P.S.; Venkatesan, R.; Nair, K.V.K.; Ravindran, M. Biofilm control for plate heat exchangers using surface seawater from the open ocean for the OTEC power plant. Int. Biodeter. Biodegr., 2004, 53(2), 133-140.

[22] Gagnadre, C.; Decossas, J.L.; Vareille, J.C. IR spectroscopic studies of polycarbonate irradiated by $\mathrm{H}+$ and $\mathrm{Li}+$ ions. Nucl. Instrum. Methods B., 1993, 73, 48-52.

[23] ASTM Standard E168-06. Standard Practices for General Techniques of Infrared Quantitative Analysis. Spectroscopy, 2006, Vol 03.06 .

[24] ASTM Standard D 638-03. Standard Test Method for Tensile Properties of Plastics. Plastics, 2003, Vol 08.01.

[25] Rutkowska, M.; Jastrzebska, M.; Janik, H. Biodegradation of polycaprolactone in sea water. React. Func. Polym., 1998, 38, 27-

[26] Pearsall, W.H.; Mortimer, C.H. Oxidation - reduction potentials in waterlogged soils.; natural waters and mud. J. Ecol., 1939, 22, 483501.

[27] Sardessai, S.; Ramaiah, N.; Kumar, S.P.; DeSousa, S.N. Influence of environmental forcings on seasonality of dissolved oxygen and nutrients in the Bay of Bengal. J. Mar. Res., 2007, 65(2), 301-316.

[28] Peter, H.D.; Robert, H.C.; Kathleen, M.H. Chlorophyll $a$ and its use as an indicator of eutrophication in the Caloosahatchee Estuary. Fla Sci., 2006, 69(1), 51-72.

[29] Ishigaki, T.; Sugano, W.; Ike, M.; Kawagoshi, Y.; Fukunaga, I.; Fujita, M. Abundance of polymers degrading microorganisms in a sea-based solid waste disposal site. J. Basic Microb. 2000, 40(3), 177-186.

[30] Azis, P.K.A.; Al-Tisan, I.; Sasikumar, N. Biofouling potential and environmental factors of seawater at a desalination plant intake. Desalination, 2001, 135, 69-82.

[31] Manzur, A.; Limon, G.M.; Favela, T.E. Biodegradation of Physicochemically Treated LDPE by a Consortium of Filamentous Fungi. J. Appl. Polym. Sci., 2004, 92, 265-271.

[32] Schmidt, P.; Dybal, J.; Turska, E.; Kulczycki, A. Conformational structure of bisphenol A polycarbonate studied by infra-red spectroscopy. Polymer, 1991, 32(10), 1862-1866.

[33] Jang, B.N.; Wilkie, C.A. The thermal degradation of bisphenol A polycarbonate in air. Thermochim. Acta, 2005, 426(1-2), 73-84.

[34] Rivaton, A. Recent advances in bisphenol-A polycarbonate photodegradation. Polym. Degrad. Stabil., 1995, 49(1), 163-79.

This is an open access article licensed under the terms of the Creative Commons Attribution Non-Commercial License (http://creativecommons.org/licenses/by$\mathrm{nc} / 3.0 /$ ) which permits unrestricted, non-commercial use, distribution and reproduction in any medium, provided the work is properly cited. 